\title{
muralpesquisa
}

\section{Marcas e baixa renda}

\begin{abstract}
A CRESCENTE IMPORTÂNCIA DA POPULAÇÃO DE BAIXA RENDA NO MERCADO DE CONSUMO, IMPULSIONADA PELO AUMENTO DA MASSA SALARIAL E ACESSO AO CRÉDITO, FOI TEMA DE INÚMEROS ESTUDOS AO LONGO DESTE ANO.
\end{abstract}

Por Marcelo Coutinho

0 mais recente deles é a pesquisa " $O$ consumo popular e a marcas", realização conjunta da Troiano Consultoria de Marca e do Ibope Inteligência. Os institutos entrevistaram mais de 3 mil consumidores com renda entre um e três salários mínimos, em nove capitais, para avaliar como quatro categorias de produtos e serviços (cervejas, fast-food, financeiras e telefonia celular) podem desenvolver negócios com esse segmento, que já corresponde a 52\% da população brasileira, de acordo com a FGV.

As entrevistas, com mais de 80 questões cobrindo aspectos como marca, distribuição, atendimento preço e comunicação, utilizaram diversas técnicas quantitativas e qualitativas para

\section{Q 63 - EM UM MOMENTO DE RESTRIÇÃO DE ORÇAMENTO/CRISE, O QUE VOCÊ DEIXARIA DE PAGAR EM PRIMEIRO LUGAR? E EM SEGUNDO LUGAR? E EM TERCEIRO LUGAR?}

Tabela - Soma das menções em primeiro lugar, por região metropolitana

\begin{tabular}{|c|c|c|c|c|c|c|c|c|c|c|}
\hline & TOTAL & $\begin{array}{c}\text { SÃO } \\
\text { PAULO }\end{array}$ & FORTALEZA & RECIFE & SALVADOR & $\begin{array}{c}\text { BELO } \\
\text { HORIZONTE }\end{array}$ & $\begin{array}{c}\text { RIO DE } \\
\text { JANEIRO }\end{array}$ & CURITIBA & $\begin{array}{c}\text { PORTO } \\
\text { ALEGRE }\end{array}$ & $\begin{array}{l}\text { DISTRITO } \\
\text { FEDERAL }\end{array}$ \\
\hline $\begin{array}{l}\text { Passeios/ } \\
\text { Lazer }\end{array}$ & $26.9 \%$ & $23.9 \%$ & $29.3 \%$ & $32,3 \%$ & $34,6 \%$ & $23,4 \%$ & $25,9 \%$ & $25,0 \%$ & $23,4 \%$ & $35,7 \%$ \\
\hline Vestuário & $15.1 \%$ & $14,2 \%$ & $17.7 \%$ & $15.6 \%$ & $15,8 \%$ & $17.3 \%$ & $15,3 \%$ & $13.6 \%$ & $12,8 \%$ & $12,2 \%$ \\
\hline $\begin{array}{l}\text { Conta de celu- } \\
\text { lar/ recarga }\end{array}$ & $15.1 \%$ & $19,0 \%$ & $10.9 \%$ & $12.9 \%$ & $12,0 \%$ & $15,8 \%$ & $12,7 \%$ & $17,1 \%$ & $17,0 \%$ & $15,3 \%$ \\
\hline $\begin{array}{l}\text { Cartão de } \\
\text { crédito }\end{array}$ & $12,1 \%$ & $12,2 \%$ & $15,0 \%$ & $8.5 \%$ & $12,8 \%$ & $10,1 \%$ & $11,5 \%$ & $18,6 \%$ & $13,3 \%$ & $9,2 \%$ \\
\hline $\begin{array}{l}\text { Carnê de paga- } \\
\text { mento de loja }\end{array}$ & $9.5 \%$ & $9.2 \%$ & $9,8 \%$ & $8.8 \%$ & $4,9 \%$ & $11.9 \%$ & $9.1 \%$ & $10,0 \%$ & $14,4 \%$ & $10,2 \%$ \\
\hline Transporte & $3.4 \%$ & $3,2 \%$ & $2,3 \%$ & $3.7 \%$ & $4,5 \%$ & $4,3 \%$ & $4,3 \%$ & $0,0 \%$ & $2,7 \%$ & $1,0 \%$ \\
\hline $\begin{array}{l}\text { Aluguel } \\
\text { da casa }\end{array}$ & $2,6 \%$ & $1,1 \%$ & $4.5 \%$ & $4.8 \%$ & $1,1 \%$ & $4,3 \%$ & $3.0 \%$ & $2,1 \%$ & $1,6 \%$ & $2,0 \%$ \\
\hline $\begin{array}{l}\text { Alimentação } \\
\text { da família }\end{array}$ & $1,0 \%$ & $1,2 \%$ & $0,8 \%$ & $0,3 \%$ & $0,4 \%$ & $1,8 \%$ & $1,2 \%$ & $0.7 \%$ & $0,5 \%$ & $0,0 \%$ \\
\hline
\end{tabular}


descobrir como as empresas podem ganhar a confiança desses consumidores. Adicionalmente, foram feitas 20 etnografias em São Paulo, Porto Alegre e Recife, para observar o dia-a-dia da população de baixa renda e seu relacionamento com as categorias mencionadas anteriormente.

Com base nas respostas e análises de cases de empresas que foram bem sucedidas para atingir o consumidor de baixa renda em outros países da América Latina, Índia e China, os pesquisadores da Troiano e do Ibope desenvolveram o Índice de Confiança Popular, que mostra as dimensões críticas, em cada mercado e categoria, para uma marca conquistar maior confiança das classes C e D. Entre as 64 marcas analisadas pelo estudo, apenas quatro atingiram um patamar razoável de "confiabilidade".

Entre as principais conclusões do trabalho, que pode ser estendido para outras categorias, estão o fato de que as classes C e D, ao contrário do senso comum, não se guiam apenas pelo preço mais em conta na hora das suas compras. Não adianta oferecer um produto mais barato com qualidade inferior. Esse consumidor não se pode dar ao luxo de "errar" na hora da compra. Um produto que quebre pouco tempo depois de adquirido pode comprometer o orçamento familiar por meses a fio, não somente pelo custo de reparo como pelo pagamento de prestações. "Depenar" produtos não é garantia de sucesso - abrir mão do design, funcionalidade e qualidade não torna as marcas mais competitivas nesse segmento.
Outra característica em comum das marcas mais aceitas por esses consumidores é a importância da comunicação na construção de uma relação confiável. Estar na mídia dá credibilidade e confere simpatia. Além disso, boas histórias envolvendo as marcas reforçam sua importância no projeto de ascensão social dessa faixa de renda. As associações feitas entre as imagens que representam as marcas com maior aceitação e as imagens que representam o futuro desejado pelos entrevistados mostraram uma enorme simetria.

Chamou a atenção também o papel que a rede de distribuição possui na vida desse consumidor. Os custos associados com transporte podem representar um gasto significativo no orçamento desses consumidores, de forma que eles privilegiam o que pode ser encontrado no comércio no entorno do domicílio em detrimento de locais que até podem oferecer preços mais baratos, mas significam gastos adicionais com deslocamento. Nas palavras de uma entrevistada, "se não tem aqui no mercadinho da esquina não entra na minha lista, é difícil a gente comprar em outro lugar".

O trabalho também mediu o impacto da crise financeira sobre este consumidor. O cartão de crédito ou carnê de loja são "despesas" que ele vai cortar somente depois de vestuário, lazer e celular, já que o nome "limpo" é garantia da continuidade do consumo, mesmo com prestações mais longas. O estudo foi desenvolvido a pedido do Grupo Meio e Mensagem, com apoio da Vivo, McDonald's, Schincariol e Losango. 